\title{
Weighing in on obesity-a sample size issue?
}

\author{
Stephen B Hanauer
}

There is no denying it. Obesity is a growing problem, worldwide. As Mello et al. discuss in an article about obesity and public health law, "Emerging research results about the economic and human costs of obesity have galvanized interest in greater governmental involvement by medicalizing the problem....and by demonstrating the stake [not steak! Ed] that each employer and taxpayer has in it" ( $N$ Engl $J$ Med [2006] 354: 2601-2610). They point out that in the US "...children are exposed to approximately 40,000 food advertisements per year, 72 percent of which are for candy, cereal and fast food" and present key regulatory targets aimed a tackling obesity from a public health law perspective. In considering personal responsibility at the employer and state level, Steinbrook (N Engl J Med [2006] 355: 753-756) discusses how the US state, West Virginia, is planning to make residents who are eligible for Medicaid sign documents that outline the responsibilities and rights of (Medicaid) participants, including the statement "I will do my best to stay healthy", which implies that members have to follow a healthy lifestyle by exercising, maintaining a healthy weight and not smoking. Failure to comply may risk a reduction in their Medicaid (i.e. health care) benefits.

One problem is that the risks conferred by obesity span a continuum, and the line of demarcation between a healthy and unhealthy weight is shifting. Those of us who previously took solace in having a slightly zaftig BMI, say 25-27, must now join the 'repenters' as accumulating data from both the US (Adams et al. N Engl J Med [2006] 355: 763-778) and Korea (Jee et al. N Engl J Med [2006] 355: 779-787) demonstrate that the risk of death, even in nonsmokers and those without chronic disease, begins to rise at a $\mathrm{BMI}$ of 25 . So, where to draw the line (or limit the scale) for the individual's ...society

needs to make

greater efforts

to provide

educational

and

regulatory (via

insurance?)

systems that

encourage

healthy habits

and habitus

SB Hanauer is Editorin-Chief of Nature Clinical Practice Gastroenterology \& Hepatology.

\section{Competing interests}

The author declared he has no competing interests.

www.nature.com/clinicalpractice doi:10.1038/ncpgasthep0636 responsibility to maintain a healthy weight might not be clear-cut.

How can we control ourselves when it comes to eating? It turns out that portion control is a perceptual problem shared by healthy weight and overweight individuals. Wansink and colleagues' simple, but elegant, studies demonstrate that we underestimate how many calories there are in a meal in proportion to increasing portion size rather than increasing waist size (Ann Intern Med [2006] 145: 326-332). In other words, the larger the portion, the greater the underestimating by persons of any BMI of its caloric value-a potential focus for package and portion control by producers. If these findings are confirmed and substantiated, food manufacturers could be coming closer to litigation over excessively caloric food packaging, which leads to documented health problems approaching the level of those caused by tobacco.

Since obesity starts in childhood, it makes most sense for public health interventions to begin with education, on the long-term health effects of (even modest) obesity - with potential parents and with children throughout their schooling. The concept of the healthy, chubby baby needs to be thrown out with the bath water. Healthy nutrition must not only be taught in the classroom, but reinforced by healthy foods (and portion sizes) served in the lunchroom. Physical education, the most easily dropped program in financially strapped education systems, needs to be prioritized back into curricula.

Finally, while we do need to emphasize that body weight, just as smoking and alcohol consumption, is a personal choice that influences health, society needs to make greater efforts to provide educational and regulatory (via insurance?) systems that encourage healthy habits and habitus. 